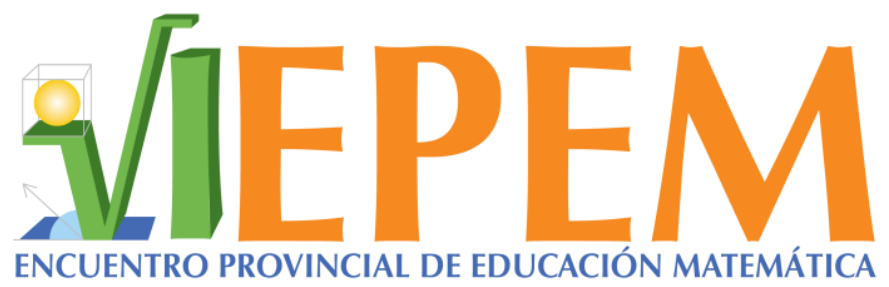

VI Encuentro Provincial de Educación Matemática.

27 al 29 de setiembre, 2017. Puntarenas, Costa Rica.

\title{
Interpretación de las medidas de posición, tendencia central y de variabilidad
}

\author{
Juan Pablo Serrano Echeverría \\ juan.serrano.echeverria@mep.go.cr \\ Ministerio de Educación Pública \\ Costa Rica
}

\begin{abstract}
Resumen
Este taller propone el análisis de una serie de problemas donde se discutirá la interpretación de la moda, media, mediana, cuartiles, desviación estándar, recorrido y recorrido intercuartílico para variables con un nivel de medición de intervalo y razón (variables cuantitativas continuas o discretas).

Se realizará énfasis en la interpretación pues es lo que se prioriza en el programa de estudios vigente. Se desea proponer una manera de trabajar este tema en las aulas, de tal forma que se propicie el análisis y el aprovechamiento del error.

Palabras clave: matemática, estadística, medidas de posición, medidas de tendencia central, variabilidad, didáctica
\end{abstract}

\section{Introducción}

Los Programas de Estudios de Matemática fueron aprobados el 21 de mayo de 2012 y consisten en una reforma significativa de los programas anteriores, ya que se pasó de un currículo basado en el cumplimiento de objetivos a uno enfocado en desarrollar habilidades para una única competencia denominada "competencia matemática". Dichas habilidades se desarrollan bajo un enfoque metodológico de resolución de problemas.

Plantea cuatro áreas matemáticas, las cuales encierran el conocimiento matemático que se cubre durante los cinco años de la educación secundaria:

Taller

Serrano, J.P. (2017). Interpretación de las medidas de posición, tendencia central y de variabilidad. En Y. Morales-López, M. Picado, R. Gamboa, C. Martínez, M. Castillo y R. Hidalgo (Eds.), Memorias del VI Encuentro Provincial de Educación Matemática, Costa Rica, 2017 (pp. 66-68). Heredia: Universidad Nacional. ISBN: 978-9968-9661-5-3. DOI:

http://dx.doi.org/10.15359/epem.6.16 
- Números

- Geometría

- Relaciones y Algebra

- Estadística y Probabilidad

Esta última área representó el cambio más significativo, en cuanto a conocimientos, con respecto a los programa de estudios anteriores y evidenció carencias en la formación docente, ya que los profesores manifestaron que durante sus estudios recibieron 1 único curso alusivo a este tema, lo que llevó a enfocar procesos de formación y capacitación continua por parte del MEP.

Durante los procesos de apoyo y observación docente por parte de la asesoría nacional de matemática, se ha evidenciado la necesidad de insistir en interpretar los resultados estadísticos obtenidos y otorgarle énfasis a esto, más que a la obtención de la medida o cálculo estadístico. Con respecto a esto, el programa de estudios vigente indica

El cálculo de medidas estadísticas no puede considerarse como un fin en sí mismo, sino como un paso para continuar con el proceso de análisis. Por ello, para simplificarlo se puede recurrir a una calculadora con funciones estadísticas o a la computadora para utilizar una hoja de cálculo o algún programa especializado. (Ministerio de Educación Pública, 2012, pág. 433)

Este taller pretende brindar los insumos necesarios y suficientes para que los docentes puedan dirigir la interpretación de las medidas estadísticas con sus estudiantes, durante los procesos de mediación y aprendizaje.

\section{Metodología del taller}

El taller se trabajará bajo el enfoque metodológico de resolución de problemas en contextos reales. Se propondrá una cantidad de problemas (entre 4 y 8 , de acuerdo con la dinámica del grupo). El taller pretende desarrollarse como propone el programa de estudios, en cuanto a la organización de la lección, la cual consta de cuatro partes: la propuesta de un

problema, el trabajo estudiantil independiente, la discusión interactiva y comunicativa y la clausura o cierre. 
Cada problema requerirá de un trabajo independiente por parte de cada participante, luego se solicitará su discusión por subgrupos, para después generar una discusión grupal y así unificar el conocimiento.

\section{Resultados esperados}

Este taller pretende que los docentes obtengan estrategias para la interpretación de las medidas estadísticas y que puedan llevarlas a cabo en el aula con sus estudiantes.

\section{Referencias}

Ministerio de Educación Pública. (2012). Programa de Estudios de Matemática. San José: Imprenta Nacional. Recuperado de http://www.mep.go.cr/sites/default/files/programadeestudio/programas/matematica. pdf

\section{(C) $(\oplus \Theta$}

Esta obra está bajo una licencia de Creative Commons Reconocimiento-NoComercialSinObraDerivada 4.0 Internacional. 